\section{RNEE}

Revista Nicolaita de Estudios Económicos

Nueva Época

Instituto de Investigaciones Económicas y Empresariales
Universidad Michoacana de San Nicolás de Hidalgo

Volumen XV, Número 1, Enero - Junio 2020, pp. 47-67

ISSN (Print): 1870 - 5464 ISSN (On-line): 2007 - 9877

DOI: $10.33110 /$ rnee.v15i1.309

\title{
El mercado interno ¿alternativa para el desarrollo económico en un escenario globalizado? Análisis comparado España, México y Corea del Sur
}

\section{The domestic market, an alternative for economic development in a global scenario? A comparative análisis: Spain, Mexico and South Korea}

\author{
Fidel Aroche Reyes ${ }^{a}$ \\ Tania Molina del Villar b* \\ Ricardo Zárate Gutiérrez ${ }^{\text {c }}$
}

\section{Resumen}

A partir del análisis de las estructuras productivas de España, México y Corea del Sur, durante los años de 1980 y los 2000, este trabajo explora si el estímulo al mercado interno es complementario al dinamismo del sector externo para alcanzar un proceso de desarrollo y crecimiento económico continuo en un escenario de alta integración internacional. La metodología empleada se inscribe en el marco del modelo Insumo-Producto y el análisis de redes; en particular, se emplea el concepto de Coeficientes Importantes (CI) con el análisis de redes. Los resultados ayudan apuntalar la hipótesis planteada, en particular que el mercado interno juega un papel central en los países con mayores y más sólidas trayectorias de crecimiento.

Palabras clave: mercado interno, articulación productiva, integración internacional, estructura económica.

Clasificación JEL: O14, O41, F63

\begin{abstract}
Based on the analysis of the productive structures of Spain, Mexico and South Korea, during the 1980s and 2000s, this paper explores whether the stimulus to the internal market is complementary to the dynamism of the external sector in order to achieve sustained economic growth and development in a of highly international integrated scenario. The input-output model and network analysis provide the framework for the methodology employed; specifically, the concept of Important Coefficients (CI) and network analysis. Results help to support the hypothesis presented, i.e., that the domestic market plays a central role in supporting the longest and most solid growth trajectories.
\end{abstract}

\footnotetext{
a Facultad de Economía, Universidad Nacional Autónoma de México.

b Departamento de Producción Económica, Universidad Autónoma Metropolitana, Unidad Xochimilco. Email: tvillar69@yahoo.com.mx

c Departamento de Producción Económica, Universidad Autónoma Metropolitana, Unidad Xochimilco

* Autor de correspondencia
} 
Keywords: domestic market, productive articulation, international integration, economic structure.

JEL Codes: O14, O41, F63

\section{Introducción}

La integración de las economías nacionales al mercado mundial es uno de los tópicos que han cobrado mayor relevancia dentro del análisis económico actual (Kaplinsky, 1998; Feenstra, 1998; Gereffi, et al, 2001; Godinez y Ángeles, 2006; Thorbecke, 2015); sin embargo, su estudio ya había sido abordado por la escuela estructuralista latinoamericana (Prebisch, 1959; Fajnzylber, 1983; Sunkel, 1991), con la peculiaridad de que éstos últimos desarrollan un enfoque integral, al enfatizar la relevancia del entorno externo, el mercado interno y la importancia del cambio estructural para alcanzar el desarrollo de las economías. De esta forma, la corriente estructuralista plantea un enfoque en el cual el desarrollo de la estructura productiva resulta fundamental para fortalecer y hacer crecer el mercado interno sin descartar el contexto económico mundial.

Desde la perspectiva de este trabajo, el fomento al mercado interno no está contrapuesto a la actual forma de organización de la producción e integración internacional y, por lo mismo, no debe descartarse como un ámbito de acción de la política económica; por el contrario, es un elemento fundamental en la medida en que coadyuva al desarrollo económico reduciendo la dependencia del mercado externo, cuya volatilidad puede someter a marcados vaivenes a las economías de menor desarrollo. En este sentido, Ortiz (2012) señala el caso de la economía China, donde su mercado interno representa entre el 60 y el $70 \%$ de la demanda total. Para este autor, el mercado interno es de gran relevancia sobre todo en un contexto en que se ha sobredimensionado el peso del comercio exterior. A diferencia de Ortiz, quien analiza la trascendencia del mercado interno desde una visión agregada y de carácter tecnológico ${ }^{1}$, en este trabajo se analiza al mercado interno a partir de la propia estructura económica, basándonos en un estudio de tipo sectorial.

En línea con lo anterior, las economías de España, México y Corea del Sur han alcanzado un grado importante de internacionalización, donde el dinamismo exportador es la constante, pero cabe preguntar si el proceso de integración a la dinámica mundial es la única vía o la más importante solución para el desarrollo económico y cuál es la relevancia del comercio internacional frente a la propia evolución del mercado interno de cada economía. Para dar respuesta a estas interrogantes, a continuación, se contrasta la importancia del mercado interno frente a la evolución de las industrias más exportadoras para definir, en última instancia, si son estrategias alternativas o complementarias dentro del proceso de desarrollo económico, empleando una metodología propia del modelo Insumo-Producto y el análisis de redes. Los años elegidos para el análisis responden a, por un lado, la inquietud de estudiar las características de las estructuras productivas durante dos períodos caracterizados cada uno por distintos modelos de desarrollo; por otro lado, debido a los cambios en el nivel de agregación de las matrices insumo-producto de la OCDE, el último año que podía homologarse con las matrices de 1980 correspondían a la primera mitad del decenio de 2000.

\footnotetext{
${ }^{1}$ Para Ortiz (2012), la importancia del mercado interno radica en tres elementos. Primero, resulta esencial para impulsar el crecimiento económico y la productividad, debido a que tecnológico y el desarrollo de capacidades permite la inversión para el progreso tecnológico y el desarrollo de capacidades productivas dinámicas propias, así como de infraestructura educativa; en segundo lugar, es un factor de atracción de tecnología externa que se introduce por medio de la IED; finalmente, el mercado interno es una pieza clave para el equilibrio en el crecimiento de largo plazo en tanto que para lograr la atracción de tecnología extranjera resulta necesario la existencia de condiciones propicias para su implantación en el país receptor. Por todo ello, el desarrollo del mercado interno es un recurso que permite reducir la dependencia del mercado externo.
} 
Para definir el peso del mercado interno dentro de economías altamente internacionalizadas, el presente documento está organizado en tres secciones. En la primera, se expone algunas ideas teórico metodológicas que guían la investigación empírica; la segunda sección está dedicada al análisis empírico del mercado interno para las tres economías y, finalmente, se presentan las conclusiones del trabajo.

\section{Aspectos teórico - metodológicos}

En la actualidad se señala la importancia de la integración de las economías nacionales al mercado mundial, centrándose en los procesos de fragmentación productiva, su descripción y las formas de inserción dentro de dicho fenómeno (Krugman, 1979; Kaplinsky, 1998; Feenstra, 1998; Gereffi, et al, 2001; Godinez y Ángeles, 2006; Thorbecke, 2015); sin embargo, no se hace mención sobre la relevancia de, por un lado, la articulación productiva y, por otro lado, el papel del mercado interno dentro de un esquema de desarrollo orientado hacia el exterior, temas centrales en este trabajo.

Las contribuciones teóricas derivadas de la Organización Industrial intentan explicar la lógica de los flujos comerciales y la actual reorganización de la producción dentro del proceso de globalización, pero omiten la importancia del desarrollo interno de las economías nacionales. Es posible agrupar este tipo de trabajos en tres diferentes enfoques, los cuales hacen referencia al proceso de fragmentación de los procesos productivos y su dispersión en diferentes espacios geográficos - incluso en distintos países. El primer conjunto describe mediante estudios de caso - las formas de organización y de participación de las empresas y los países en el proceso de intercambio; básicamente son estudios dedicados al análisis de la globalización y a las cadenas productivas(Gereffi, 2001;Gereffi, et.al., 2001; Kaplinsky, 1998; Kaplinsky y Kaplan, 1999). Una segunda visión, se concentra fundamentalmente en los estudios de economías nacionales, pese a reconocer la relevancia de las grandes empresas multinacionales; o mejor dicho, su objeto de análisis es propiamente el comercio internacional entre países. Dentro de esta vertiente, Hummels, et al. (1999) señalan que junto al incremento del comercio mundial, ocurrieron cambios en la naturaleza del comercio, entre los que destaca la creciente interconexión de los proceso de producción en una cadena de comercio vertical, desplegada a través de diversos países, especializándose cada uno de ellos en etapas particulares de la secuencia de producción de bienes. La tercera vertiente intenta encontrar en la teoría del comercio internacional la explicación al proceso de fragmentación productiva; al tiempo que analiza el impacto que tiene la subcontratación dentro del proceso de integración en términos de la distribución del ingreso para los países (Feenstra, 1998).

Desde la perspectiva de esta investigación, los anteriores enfoques presentan debilidades importantes. Por un lado, muestran cierta parcialidad al omitir las consecuencias de la globalización para los procesos de industrialización, crecimiento y desarrollo de los países menos desarrollados. Por otro lado, no reconocen que las principales beneficiarias de la globalización son las empresas multinacionales, al apropiarse de las ganancias de la fragmentación, sin que necesariamente esto conlleve un beneficio para las economías nacionales en términos de empleo, bienestar, crecimiento del ingreso y productividad. En síntesis, desde la evidencia empírica, es claro que para muchos países en desarrollo, la fragmentación productiva provoca desarticulación y bajo crecimiento debido a que las ganancias del comercio quedan restringidas a unos cuantos sectores, lo que podría provocar estructuras económicas polarizadas.

De esta manera, la concepción del comercio internacional y la producción fragmentada en distintos espacios geográficos deja al margen el análisis del desarrollo de las economías nacionales, específicamente, del papel que podrían jugar los mercados internos y la articulación de la estructura productiva. El modelo IP proporciona un marco de referencia para el estudio de estas cuestiones; en efecto, su preocupación central es la 
interdependencia entre los sectores productores y entre éstos y los componentes de la demanda final, incluidas la demanda interna y las exportaciones (Miller y Blair, 2009).

Como se sabe, el análisis cualitativo es una de las extensiones del modelo IP, que comúnmente transforma la matriz de coeficientes técnicos $\mathrm{A}=\left\{\mathrm{a}_{i j}\right\}$ en un arreglo binario de adyacencias ${ }^{2} \mathrm{~W}=\left\{\mathrm{w}_{i j}\right\}$, al que se asocia un grafo que muestra las conexiones entre cada par de sectores $i, j$ en el conjunto de ramas del sistema; es decir, se dice que si $a_{i j} \geq 0, i$ es adyacente a $\mathrm{y} \mathrm{w}_{\mathrm{ij}}=1$. La teoría de grafos (Harary, 1969) proporciona las herramientas que permiten estudiar el resultado. Alternativamente, este grafo puede entenderse como una red y para su análisis resulta útil tal teoría, en la medida en que su aplicación dentro del ámbito IP permite simplificar el esquema de relaciones intersectoriales, al integrar dentro de su análisis elementos relevantes como la posición relativa de los distintos sectores, su orientación y los senderos por donde circula la influencia económica dentro de una estructura (García y Ramos, 2003).

Frecuentemente resulta conveniente elegir un subconjunto de las conexiones entre las ramas, de acuerdo con algún criterio de análisis, de otro modo, pueden resultar grafos o redes muy complejas, sin que necesariamente se agreguen resultados relevantes.

En este trabajo hemos construido la matriz binaria de adyacencias $\mathrm{W}=\left\{\mathrm{w}_{i j}\right\}$ eligiendo los coeficientes importantes $(\mathrm{Cl})$, con un filtro de $20 \%$. Un Cl aparecerá cuando a $i j$ que conecta a dos sectores directamente, implica también que estén también indirectamente conectados por una serie larga de relaciones entre ellos. Esto es, aquellos coeficientes técnicos que involucren mayores secuencias de conexiones indirectas, o conjunto de secuencias, serán 'importantes' para la economía, debido a que sus transacciones implican intercambios con un mayor número de sectores (Aroche, 1996 y 2002).

La solución del modelo insumo - producto (IP) está dada por $=(\mathrm{l}-\mathrm{A})^{-1} \mathrm{y}=\mathrm{Ly}$ si la demanda final (y) cambia, en alguna proporción, el vector x cambiará también. Asimismo, si alguna entrada de la matriz A y por lo tanto en la matríz L) aumenta o disminuye, manteniéndose la demanda final estática, el vector x cambiará también en alguna proporción. Los coeficientes aij cuya modificación provocan mayores mudanzas en las entradas del vector x se consideran importantes. El coeficiente de sensibilidad se calcula según la siguiente expresión (Schinkte y Stäglin, 1988):

$$
\mathrm{r}_{\mathrm{ij}}=\frac{1}{a_{i j}\left[\mathrm{a}_{\mathrm{ij}}+\mathrm{a}_{\mathrm{ii}}\left(\mathrm{T}_{\mathrm{i}} / \mathrm{T}_{\mathrm{j}}\right)\right]}
$$

Donde $\mathrm{a}_{i j}$ es un elemento en la matriz de coeficientes técnicos A; $\alpha_{i j}$ es un elemento en la matriz inversa de Leontief L; $\alpha_{\mathrm{ii}}$ es un elemento en la diagonal principal de L; $\mathrm{x}_{\mathrm{i}}$; es el producto bruto del sector $i$ - ésimo y $\mathrm{x}_{j}$ es el producto bruto del sector $i$ - ésimo. $\mathrm{Si} \mathrm{r}_{i j} \leq 0.5$, $a_{i j}$ es un $\mathrm{Cl}$, de tal forma que un coeficiente será 'importante' si una mínima variación en él provoca grandes cambios en el producto (Aroche, 1996, Tarancón, 2004).

Si la demanda final está dada y se presentan ciertos cambios en algunas entradas (o celdas) de A, habrá variaciones de diversa magnitud en L y en x, las cuales están sujetas a la estructura productiva característica de cada economía Es decir, entre más compleja sea la estructura productiva, mayores son los efectos del cambio en los elementos de la matriz A y en el vector x (Aroche, 2005: 34). Al mismo tiempo, los cambios en los coeficientes técnicos, así fueran en la misma cuantía, no tienen un efecto homogéneo en las transacciones indirectas ni en la producción de los diferentes sectores. Es decir, los cambios en las entradas de la matriz A, provocan impactos

\footnotetext{
${ }^{2}$ Esta transformación puede hacerse también sobre la matriz de intercambios $Z=\left\{z_{i j}\right\}$, sobre la matriz de entregas $E=\left\{e_{i j}=z_{i j} / x_{i}\right\}$ o sobre la matriz inversa de Leontief $L=\left\{\square_{i j}\right\}$, por ejemplo, en función de los objetivos del análisis.
} 
diferenciados en las entradas de la matriz L y en el vector x, con lo cual es posible distinguir a los coeficientes $a_{i j}$ por sus impactos potenciales. De ahí, que un cambio por pequeño que sea en el valor de un Cl tendrá grandes efectos en el producto de muchos otros sectores y, por lo tanto, en la economía. Para determinar cuáles coeficientes son importantes, se adopta la convención de que un coeficiente es importante si un cambio inferior al 20 por ciento provoca una modificación en la producción sectorial no superior al uno por ciento.

El estudio empírico de los tres países estudiados se basa en el cálculo de los Cl con las matrices IP de transacciones internas y su aplicación dentro del análisis de redes con el empleo del programa NodeXL de la Fundación de Investigación de Medios Sociales (Social Media Research Foundation). Dicho programa permite agregar dos criterios adicionales: en nuestro caso, un vector con la información del consumo autónomo privado como proporción del total de bienes y servicios producidos y ofertados en cada economía como indicativo del mercado interno, y un segundo vector con la participación de cada sector en las exportaciones totales, para distinguir a las ramas orientadas al mercado mundial. Se construye la gráfica asociada a la matriz de adyacencia W, del tipo que aparece en la Figura 1 1con datos hipotéticos (así como Gráficas 1, 2 y 3, construidas con datos reales).

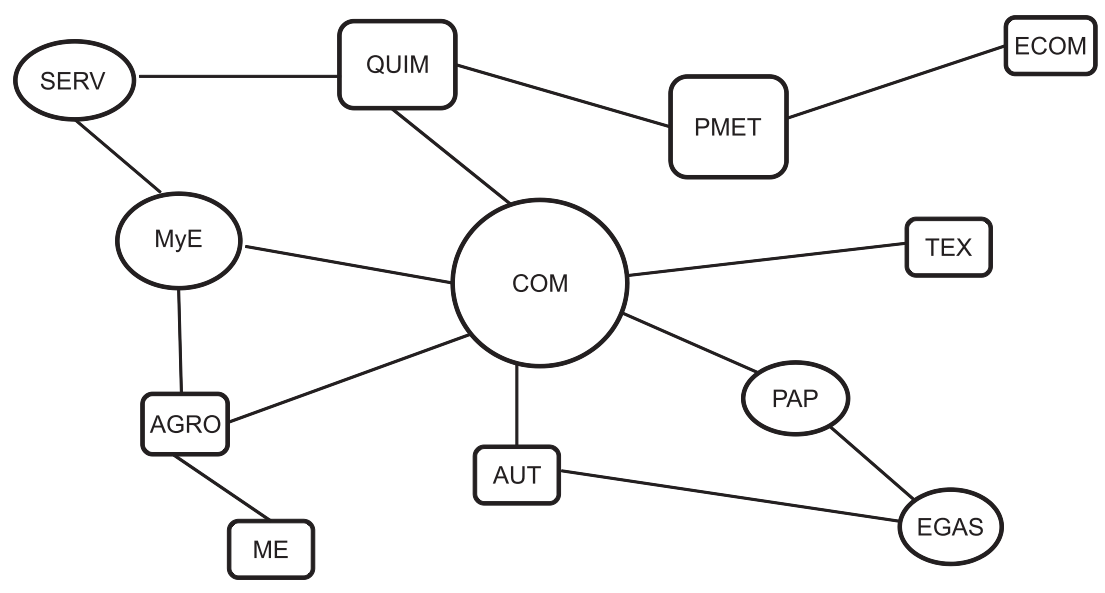

Con la matriz de adyacencias $\mathrm{W}$ y los vectores asociados a los mercados interno y externo quedan definidas las siguientes características que pueden tener los distintos nodos en la red:

1. El tamaño del nodo define a las actividades orientadas al mercado interno. Esto es, a mayor tamaño, más grande es la proporción del consumo autónomo; si por el contrario, el vértice es menor, indicara una menor orientación al mercado interno.

2. Debido a que existen actividades con doble orientación; es decir, son altamente exportadoras y al mismo tiempo presentan un alto consumo autónomo, es preciso agregar la forma del nodo como otro rasgo distintivo. Así, si el nodo es cuadrado y de mayor tamaño, se trata de una rama de doble orientación, si el vértice es 
cuadrado y de menor tamaño, la actividad es netamente exportadora y si el nodo es redondo y de gran tamaño la rama tiene una orientación fundamentalmente interna. Para el caso hipotético representado en la Figura 1, Maquinaria y equipo (ME) es una rama principalmente exportadora, la Química (QUIM), presenta doble orientación y Comercio (COM) es una actividad orientada al mercado interno.

3. La capacidad de articularse con el sistema económico, ya sea como oferente o demandante de bienes y servicios, se determina por la centralidad del nodo, definida por el número de enlaces que establece un nodo (sector) con otros nodos. Independientemente, de su carácter exportador o el tipo de orientación productiva que tenga (mercado interno o externo), los sectores más articulados aparecen en el centro de la gráfica, mientras en la periferia quedan las industrias más desvinculadas del resto de las industrias de la red.

La base de datos empleada proviene de distintas fuentes de información. Las tablas IP de 1980 se recopilaron respectivamente del Instituto Nacional de Estadística (INE) de España, el Banco de Corea y el Instituto Nacional de Estadística, Geografía e Informática (INEGI) de México. Las tablas del segundo periodo provienen del STAN Structural Analysis Database (Base de données STAN pourl'AnalyseStructurelleOCDE), 2003 para México y 2005 para España y Corea. Debido a que la información no es directamente compatible por la diversidad de fuentes de información, fue indispensable homologar y agregar las distintas matrices de acuerdo al anexo metodológico de Molina (2016). De esta forma, al tomar como base la agregación de la OCDE quedaron definidas 30 ramas homogéneas (Cuadros 2, 4 y 6).

\section{Mercado interno alternativa o complementariedad al desarrollo}

El comercio con el exterior se concibe como una de las principales fuentes de crecimiento económico por su capacidad para dinamizar a la actividad económica. De esta forma, ya sea del lado post-keynesiano (Kaldor, 1966; Thirlwall, 2003), como de posturas más ortodoxas (Samuelson, 1948; Balassa, 1989; Krueger, 1990), o visiones más heterodoxas (Krugman 1979;Kaplinsky, 1998; Kaplinsky y Kaplan, 1999; Hummels, et al., 1999; Feenstra, 1998; Gereffi, 2001;Gereffi, et.al., 2001, entre otros), se sostiene que el sector exportador y la integración a la economía mundial son esenciales para alcanzar el crecimiento en el largo plazo, pero se omite el análisis del mercado interno por no resultar relevante desde tales posturas teóricas.

Sin negar la importancia de la demanda y la oferta externas como fuente del crecimiento, resulta indispensable un análisis más integral que no olvide las partes fundamentales de un sistema económico y, entre ellas, destaca el mercado interno. Por lo anterior, mediante el análisis de redes que se presenta a continuación planteamos estudiar tres experiencias diferentes: España, Corea del Sur y México, en dos momentos históricos caracterizados por distintos modelos de desarrollo económico. Tres economías que no solo se distinguen por ser altamente internacionalizadas, con sectores exportadores muy activos en términos tecnológicos y productivos, sino que también cuentan con una extensa población ${ }^{3}$, lo que hace suponer la existencia de extensos mercados internos. Para fines de exposición se subdivide la sección en tres apartados, cada uno dedicado a un país.

\footnotetext{
${ }^{3}$ De acuerdo a datos poblacionales del Banco Mundial (DATABANK), Instituto Nacional de Estadística, Geografía e Informática (INEGI, México), del instituto Nacional de Estadística (INE, España) y de la Oficina Nacional de Estadística (Corea del Sur), México, tiene una población de 114 millones de habitantes (densidad poblacional de 57 hab/Km2), España, 46 millones (con una densidad de población de 93 hab/km2) y Corea del Sur, 49 millones de habitantes (densidad poblacional de $487.7 \mathrm{hab} / \mathrm{km} 2$ ).
} 


\subsection{La desarticulación del mercado interno y las actividades exportadoras en España}

La forma de participación de España en la actual configuración internacional de las relaciones productivas y comerciales, ha conducido a este país a una disminución importante del número de ramas con mayor orientación interna. En 1980, siete aparecen como netamente exportadoras (Química, Maquinaria y equipo, Equipo de transporte, Hierro, Textiles, Alimentos y Transportes diversos) y solo dos cumplen la doble función de proveer a los dos mercados (Petróleo y carbón y Productos agrícolas), las otras veintiuna actividades son de alto consumo autónomo (Ver Cuadro 2). Para 2005 disminuye tanto la cantidad de ramas con mayor orientación interna a 18, como las de doble orientación, mientras el aumento en el número de industrias exportadoras se explica principalmente por la consolidación de los sectores previamente exportadores y el cambio de orientación de cuatro industrias, dos que en 1980 tenían un alto consumo autónomo (Negocios y Equipo de cómputo) y las dos que anteriormente presentaban una doble orientación (Petróleo y Productos agrícolas).

A la reducción en los sectores de mayor orientación al mercado interno, corresponde también cambios en las participaciones en valor agregado, exportaciones e importaciones. Como es lógico, se reduce la contribución de este tipo de industrias en valor agregado, de 63 a 55 por ciento. Lo que ya no resulta tan lógico es el incremento en su contribución de un punto porcentual en las exportaciones pero, sobre todo, en las importaciones - de más de 10 puntos (Cuadro 1).

España

Contribución en valor agregado, exportaciones e importaciones por

Cuadro 1 tipo de mercado, 1980 y 2005 (porcentajes de participación)

\begin{tabular}{lcccccc}
\hline & \multicolumn{2}{c}{ Valor Agregado } & \multicolumn{2}{c}{ Exportaciones } & \multicolumn{2}{c}{ Importaciones } \\
& 1980 & 2005 & 1980 & 2005 & 1980 & 2005 \\
\hline Industrias orientadas al mercado interno & 63.5 & 55.2 & 17.7 & 18.8 & 14.5 & 26.0 \\
Industrias con doble orientación & 13.6 & 8.1 & 6.7 & 6.2 & 17.6 & 0.4 \\
Industrias netamente exportadoras & 22.8 & 36.7 & 75.6 & 75.0 & 69.4 & 73.5 \\
\hline
\end{tabular}

Fuente: Elaboración propia con datos derivados de las tablas insumo-producto de 1980 del Instituto Nacional de Estadística (INE), España y de 2025 del STAN, Structural Analysis Database, OCDE.

Los datos anteriores corroboran la internacionalización de la economía española, aún en las ramas cuya vocación prioritaria es el mercado interno. Por un lado, resulta notable el incremento del componente de importaciones en la producción; esto es, la razón entre las importaciones y el valor bruto de la producción (M/VBP) tiende a aumentar, en tanto disminuye la relación valor agregado - valor bruto de la producción (VA/VBP). Por otro lado, la proporción de la producción interna que se destina al mercado internacional aumenta - exportaciones entre valor de la producción (X/VBP). Esta evolución también tiene lugar en el caso de las industrias exportadoras (Cuadro 2). 
España Comportamiento de las industrias por tipo de mercado, 1980 y 2005

\begin{tabular}{|c|c|c|c|c|c|c|c|c|c|c|c|}
\hline \multirow[b]{2}{*}{ Industrias por tipo de mercado } & \multicolumn{4}{|c|}{1980} & \multirow[b]{2}{*}{$\begin{array}{c}\text { Particip } \\
\%\end{array}$} & \multirow[b]{2}{*}{ Industrias por tipo de mercado } & \multirow[b]{2}{*}{ VANBP } & \multicolumn{3}{|c|}{2005} & \multirow[b]{2}{*}{$\begin{array}{c}\text { Particip } \\
\%\end{array}$} \\
\hline & VANBPP & $X / V B P$ & $M / N B P$ & Grado & & & & $X N B P$ & $M N B P$ & Grado & \\
\hline (26) NEG & 0.016 & 0.003 & 0.016 & 7 & 3.6 & (23) TELE & 0.513 & 0.018 & 0.032 & 5 & 2.3 \\
\hline (23) TELE & 0.888 & 0.060 & 0.040 & 4 & 2.0 & (24) FIN & 0.643 & 0.028 & 0.043 & 7 & 3.3 \\
\hline (24) FIN & 0.744 & 0.031 & 0.012 & 3 & 1.5 & (26) NEG & 0.656 & 0.060 & 0.112 & 13 & 6.0 \\
\hline (13) MyE & 0.726 & 0.044 & 0.590 & 3 & 1.5 & (15) MELEC & 0.434 & 0.158 & 0.219 & 6 & 2.8 \\
\hline (15) MELEC & 0.487 & 0.116 & 0.271 & 7 & 3.6 & (2) MIN & 0.980 & 0.001 & 0.953 & 1 & 0.5 \\
\hline (18) EGAS & 0.424 & 0.007 & 0.000 & 4 & 2.0 & (18) EGAS & 0.410 & 0.001 & 0.002 & 6 & 2.8 \\
\hline (2) MIN & 0.972 & 0.010 & 0.907 & 1 & 0.5 & (10) MnM & 0.409 & 0.051 & 0.134 & 11 & 5.1 \\
\hline (7) PET & 0.302 & 0.010 & 0.140 & 18 & 9.2 & (12) PMET & 0.353 & 0.121 & 0.058 & 8 & 3.7 \\
\hline (6) PAP & 0.387 & 0.052 & 0.157 & 5 & 2.6 & (9) PLAS & 0.371 & 0.156 & 0.092 & 6 & 2.8 \\
\hline (10) $\mathrm{MnM}$ & 0.340 & 0.129 & 0.053 & 9 & 4.6 & (29) APUB & 0.815 & 0.001 & 0.002 & 2 & 0.9 \\
\hline (25) ALBI & 0.780 & 0.001 & 0.004 & 3 & 1.5 & (5) MAD & 0.424 & 0.012 & 0.222 & 14 & 6.5 \\
\hline (29) APUB & 0.508 & 0.001 & 0.014 & 2 & 1.0 & (19) CONST & 0.453 & 0.001 & 0.000 & 2 & 0.9 \\
\hline (19) CONST & 0.410 & 0.003 & 0.000 & 5 & 2.6 & (25) ALBI & 0.754 & 0.005 & 0.008 & 5 & 2.3 \\
\hline (30) SERV & 0.588 & 0.034 & 0.059 & 5 & 2.6 & (1) AGRO & 0.639 & 0.011 & 0.141 & 7 & 3.3 \\
\hline (21) HOTR & 0.623 & 0.103 & 0.073 & 7 & 3.6 & (17) MANUF & 0.427 & 0.143 & 0.185 & 13 & 6.0 \\
\hline (5) MAD & 0.176 & 0.271 & 0.026 & 7 & 3.6 & (30) SERV & 0.335 & 0.025 & 0.034 & 13 & 6.0 \\
\hline (3) ALI & 0.286 & 0.029 & 0.077 & 3 & 1.5 & (21) HOTR & 0.446 & 0.045 & 0.075 & 5 & 2.3 \\
\hline (28) SALUD & 0.524 & 0.000 & 0.003 & 10 & 5.1 & (6) PAP & 0.429 & 0.072 & 0.119 & 8 & 3.7 \\
\hline (27) EDU & 0.784 & 0.000 & 0.004 & 3 & 1.5 & (3) ALI & 0.380 & 0.041 & 0.130 & 4 & 1.9 \\
\hline \multirow[t]{2}{*}{ Industrias orientadas al Mercado Interno } & 0.524 & 0.048 & 0.129 & 106 & 54.1 & (28) SALUD & 0.691 & 0.001 & 0.060 & 5 & 2.3 \\
\hline & & & & & & (27) EDU & 0.560 & 0.000 & 0.007 & 1 & 0.5 \\
\hline (8) QUIM & 0.417 & 0.076 & 0.213 & 13 & 6.6 & Industrias orientadas al Mercado Interno & 0.530 & 0.045 & 0.125 & 142 & 66.0 \\
\hline (1) AGRO & 0.755 & 0.045 & 0.191 & 6 & 3.1 & & & & & & \\
\hline \multirow[t]{2}{*}{ Industrias con doble orientación } & 0.586 & 0.060 & 0.202 & 19 & 9.7 & (11) HIE & 0.354 & 0.131 & 0.200 & 8 & 3.7 \\
\hline & & & & & & (20) COM & 0.604 & 0.098 & 0.020 & 16 & 7.4 \\
\hline (14) ECOM & 0.486 & 0.307 & 0.293 & 5 & 2.6 & Industrias con doble orientación & 0.479 & 0.115 & 0.110 & 24 & 11.2 \\
\hline (16) ETRANS & 0.524 & 0.194 & 0.343 & 3 & 1.5 & & & & & & \\
\hline (11) $\mathrm{HIE}$ & 0.298 & 0.170 & 0.189 & 11 & 5.6 & (14) ECOM & 0.451 & 0.465 & 0.269 & 5 & 2.3 \\
\hline (9) PLAS & 0.322 & 0.292 & 0.110 & 6 & 3.1 & (13) MyE & 0.441 & 0.205 & 0.236 & 6 & 2.8 \\
\hline (12) PMET & 0.345 & 0.400 & 0.125 & 6 & 3.1 & (8) QUIM & 0.373 & 0.221 & 0.215 & 13 & 6.0 \\
\hline (20) COM & 0.688 & 0.122 & 0.012 & 17 & 8.7 & (16) ETRANS & 0.268 & 0.415 & 0.067 & 5 & 2.3 \\
\hline (4) TEX & 0.275 & 0.356 & 0.057 & 7 & 3.6 & (7) PET & 0.414 & 0.204 & 0.160 & 6 & 2.8 \\
\hline (17) MANUF & 0.375 & 0.493 & 0.078 & 9 & 4.6 & (4) TEX & 0.445 & 0.269 & 0.203 & 5 & 2.3 \\
\hline (22) TRANS & 0.505 & 0.309 & 0.083 & 7 & 3.6 & (22) TRANS & 0.511 & 0.277 & 0.145 & 9 & 4.2 \\
\hline Industrias netamente exportadoras & 0.424 & 0.294 & 0.143 & 71 & 36.2 & Industrias netamente exportadoras & 0.415 & 0.294 & 0.185 & 49 & 22.8 \\
\hline
\end{tabular}

Nota: VA / VBP = Relación Valor Agregado y Valor Bruto de la Producción; X / VBP = Parte de la producción destinada a las exportaciones; $\mathrm{M} / \mathrm{VBP}=$ Componente de Importaciones.

Fuente: Elaboración propia con datos de las matrices insumo - producto de 1980 de Economic Statistics System, The Bank of Korea,

Si al dato de participación en las variables económicas añadimos los indicadores del análisis de redes, encontramos no solo la tendencia a la contracción relativa del mercado interno, sino también confirmamos la evidente pérdida de articulación de este tipo de sectores con el aparato productivo nacional. La reducción en el número y participación de los grados - o vinculaciones importantes - es explicada por las tres industrias que dejan de tener mayor vocación interna (Negocios, Equipo de Cómputo y Comercio); el número de grados promedio del grupo se reduce de 5.3 a 4.8 y el carácter periférico que van adquiriendo un gran número de este tipo de industrias dentro de la red de interconexiones.

Lo anterior se deduce de la observación de la Gráfica 1, que nos indica que mientras en 1980 los sectores de vocación interna son los que se encuentran fundamentalmente en una posición central en la red (ejemplo, Comercio, Papel, Otras Manufacturas y Finanzas); para 2005, dos actividades exportadoras, Comercio y Negocios, son las que ocupan los lugares centrales. Ello, sin embargo, no equivale a decir que las industrias exportadoras sean importantes demandantes de insumos a las ramas nacionales. Por el contrario, si se observa la gráfica es posible apreciar que justo los sectores netamente exportadores de mayor participación en las ventas al exterior, son los más fuertemente relacionados con el sector externo como fuente de insumos - Equipo de transporte, Química, Alimentos y, en menor medida, Servicios de Transporte. 


\section{Gráfica 1}

\section{España}

Red de interrelaciones por tipo de mercado

Vinculaciones Importantes, 1980

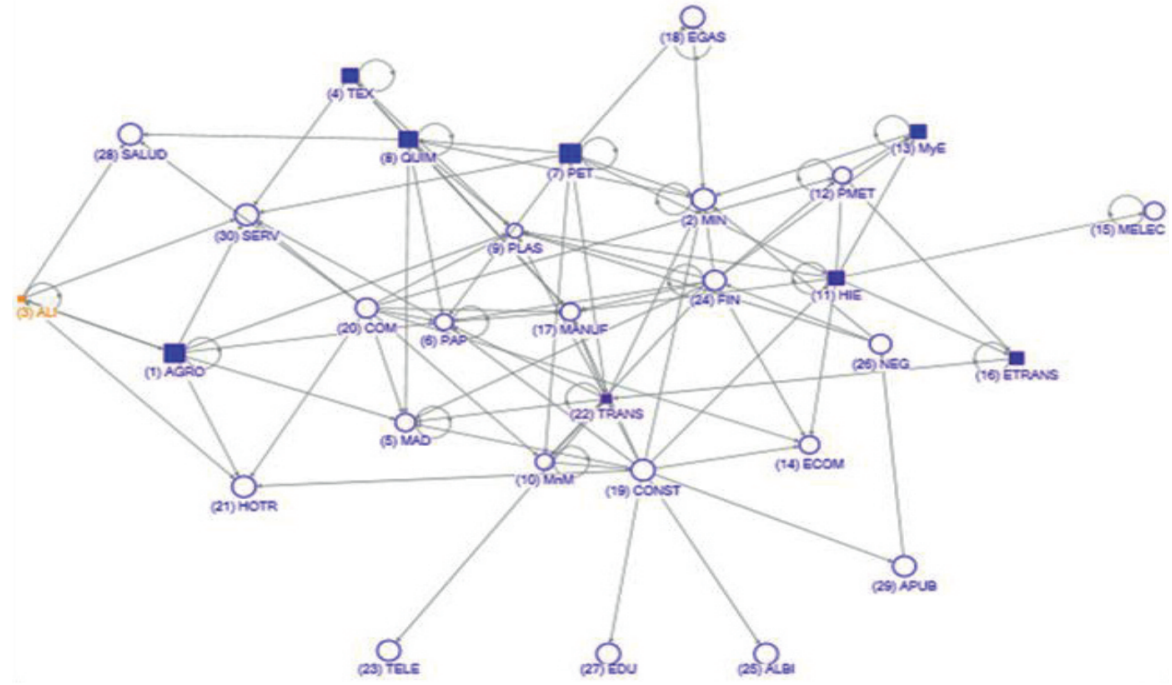

Vinculaciones Importantes, 2005

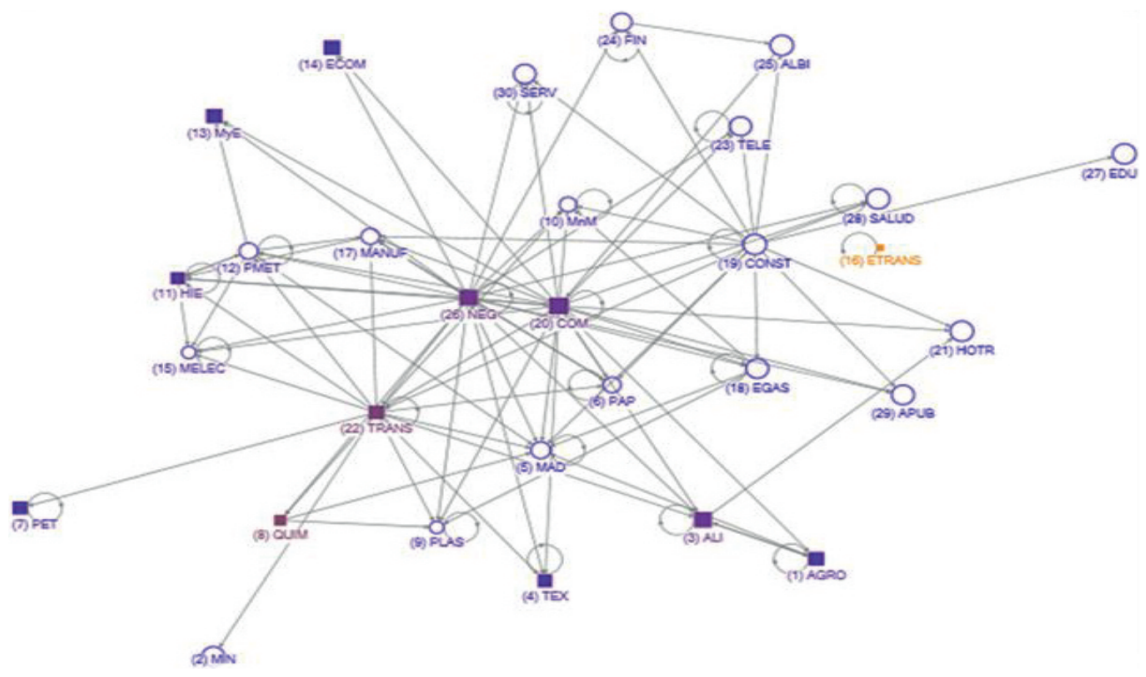

Fuente: Elaborado a partir de las matriz insumo - producto, publicado por INE, España, 1980 y STAN (OCDE), 2008 
En conclusión, la participación de España dentro de la actual configuración internacional de las relaciones productivas y comerciales, evidencia su proyección internacional con una disminución importante del número de industrias con vocación interna. Podemos asegurar que, en términos comparativos entre 1980 a 2005, el mercado interno tiende a deprimirse, pese al auge que presenta la economía española desde los noventa hasta la primera mitad del decenio de 2000. Lo anterior se observa en la disminución del número de industrias destinadas a dicho mercado, con la consiguiente reducción en el aporte en el valor agregado de más de 10 puntos porcentuales, y un incremento significativo de las importaciones (participaciones y contenido de importaciones para la producción) como en una disminución del número de grados y la pérdida de centralidad de los sectores con alto consumo autónomo.

Como se observa con los datos anteriores, la economía española se inserta exitosamente en la dinámica mundial integrándose a la Unión Europea, donde mantiene relaciones de intercambio que pueden caracterizarse como intraindustriales. Sin lugar a dudas, ello demuestra la participación del país dentro del proceso de fragmentación y deslocalización productiva, en el cual las industrias netamente exportadoras se caracterizan por su elevada intensidad tecnológica y una baja articulación con el sistema productivo nacional. De otro lado, un mercado interno contraído en el que predominan las actividades de bajo dinamismo y poco articuladas. Tal comportamiento confirma una evolución comercial semejante a lo que menciona la nueva Teoría del Comercio Internacional, pero que desde el punto de vista de nuestra investigación, patentiza la existencia de elementos que podrían limitar el potencial de crecimiento sostenido de dicha economía, descuidando el amplio mercado interno que posee- tal como lo señalaban los postulados de la escuela estructuralista latinoamericana.

\subsection{México: Dinamismo exportador vs Mercado Interno}

Para el caso de México, la distinción entre las diferentes industrias por el tipo de mercado de destino de la producción hace notoria la importancia del mercado interno y el creciente grado de internacionalización del sistema productivo. No obstante, esto no necesariamente es sinónimo de que la economía siga una trayectoria de crecimiento equilibrada y sostenida, sino una marcada separación entre los dos tipos de actividades.

Pese a que, entre 1980 y 2003, el número de sectores orientados al mercado interno se mantiene en veintidós (de treinta), no son las mismas ramas. Al mismo tiempo, encontramos que mientras en el primer año, existía igual cantidad de sectores con doble orientación y aquellos dirigidos al mercado de exportación, para 2003 esta condición desaparece, de tal manera que las actividades presentan características de ser netamente exportadoras o estar dirigidas al mercado interno. De esta manera, para 1980 los sectores de doble orientación son Productos agrícolas, Alimentos, Textiles y Servicios de Transporte; en tanto las actividades netamente exportadoras: Petróleo, Hoteles, Comercio y Minería, las 22 industrias de alto consumo autónomo se pueden apreciar en el Cuadro 4.

Para 2003, se presentan cambios muy importantes en los diferentes tipos de actividades. Dentro de las ramas dedicadas a proveer al mercado interno, se mantienen 18, siendo Productos agrícolas, Alimentos, Petróleo y carbón, y Hoteles y restaurantes, las que eran exportadoras y en el último año son parte del grupo de industrias dirigidas al mercado interno. En contraparte, los sectores orientados al mercado de exportación se consolidan, aun perdiendo su capacidad de proveer a ambos mercados, se mantienen 4 de los sectores previamente exportadores (Comercio, Textiles, Minería y Servicios de transporte), se añade a ésta lista Equipo de cómputo, Maquinaria eléctrica, Equipo de transporte y Otras manufacturas. Llama la atención que Comercio se encuentre en este grupo exportador, cuando es lógico suponer que tendría una doble orientación. 
México

Contribución en valor agregado, exportaciones e importaciones por

Cuadro 3 tipo de mercado, 1980 y 2003 (porcentajes de participación)

\begin{tabular}{lcccccc}
\hline & \multicolumn{3}{c}{ Valor Agregado } & \multicolumn{2}{c}{ Exportaciones } & \multicolumn{2}{c}{ Importaciones } \\
& 1980 & 2003 & 1980 & 2003 & 1980 & 2003 \\
\hline \multirow{2}{*}{ Industrias orientadas al mercado interno } & 46.9 & 61.3 & 15.8 & 19.7 & 69.0 & 49.4 \\
Industrias con doble orientación & 22.9 & $-\ldots$ & 16.3 & $-\ldots$ & 21.5 & $-\ldots$ \\
Industrias netamente exportadoras & 30.2 & 38.7 & 67.8 & 80.3 & 9.6 & 50.6 \\
\hline
\end{tabular}

Fuente: Elaboración propia con datos de las matrices insumo-producto de 1980 del Instituto Nacional de Estadística,

Geográfica e informática (INE), México y de 2023 del STAN, Structural Analysis Database, OCDE.

Los resultados de las contribuciones de las exportaciones, las importaciones y el valor agregado en el Cuadro 3 resumen perfectamente las características distintivas de cada período. Así, en el año de 1980, la información estadística ilustra la enorme dependencia sobre las importaciones que tenían -particularmente las ramas dedicadas a abastecer al mercado interno. En cuanto a la participación en el valor agregado y las exportaciones, sin lugar a dudas se aprecia el fuerte peso de los sectores orientados al mercado interno en la primera variable y la baja capacidad exportadora de las mismas. En contraste, las actividades netamente exportadoras, con una participación del 68\%, que sólo absorbía el10\% de las importaciones y generaban el 30\% del valor agregado. En tanto, los sectores de doble orientación, tenían un comportamiento semejante al del primer grupo, bajo peso en las exportaciones y una participación considerable en el valor agregado y las importaciones. 
México

Comportamiento de las industrias por tipo de mercado, 1980 y 2003

\begin{tabular}{|c|c|c|c|c|c|c|c|c|c|c|c|}
\hline \multirow[b]{2}{*}{ Industrias por tipo de mercado } & \multicolumn{4}{|c|}{1980} & \multirow[b]{2}{*}{$\begin{array}{l}\text { Particip } \\
\%\end{array}$} & \multirow[b]{2}{*}{ Industrias por tipo de mercado } & \multicolumn{5}{|c|}{2003} \\
\hline & VANBPP & $X N B P$ & MNBP & Grado & & & VANBP & $X N B P$ & $M / V B P$ & Grado & $\begin{array}{l}\text { Particip } \\
\%\end{array}$ \\
\hline (24) FIN & 0.780 & 0.001 & 0.019 & 2 & 1.3 & (23) TELE & 0.621 & 0.029 & 0.017 & 5.0 & 3.0 \\
\hline (26) NEG & 0.798 & 0.002 & 0.003 & 6 & 3.8 & (24) FIN & 0.647 & 0.038 & 0.074 & 4.0 & 2.4 \\
\hline (23) TELE & 0.843 & 0.096 & 0.039 & 4 & 2.5 & (13) MyE & 0.778 & 0.180 & 0.645 & 2.0 & 1.2 \\
\hline (14) ECOM & 0.547 & 0.102 & 0.158 & 5 & 3.1 & (8) QUIM & 0.560 & 0.078 & 0.344 & 11.0 & 6.6 \\
\hline (15) MELEC & 0.618 & 0.058 & 0.232 & 4 & 2.5 & (18) EGAS & 0.393 & 0.004 & 0.000 & 7.0 & 4.2 \\
\hline (13) MyE & 0.788 & 0.023 & 0.569 & 2 & 1.3 & (6) PAP & 0.550 & 0.080 & 0.309 & 5.0 & 3.0 \\
\hline (8) QUIM & 0.525 & 0.035 & 0.147 & 7 & 4.4 & (7) PET & 0.267 & 0.057 & 0.120 & 4.0 & 2.4 \\
\hline (16) ETRANS & 0.544 & 0.041 & 0.267 & 3 & 1.9 & (10) $\mathrm{MnM}$ & 0.582 & 0.106 & 0.113 & 6.0 & 3.6 \\
\hline (6) PAP & 0.526 & 0.012 & 0.116 & 3 & 1.9 & (11) HIE & 0.557 & 0.110 & 0.307 & 4.0 & 2.4 \\
\hline (18) EGAS & 0.562 & 0.035 & 0.003 & 3 & 1.9 & (9) PLAS & 0.668 & 0.155 & 0.506 & 4.0 & 2.4 \\
\hline (9) PLAS & 0.513 & 0.012 & 0.115 & 5 & 3.1 & (12) PMET & 0.621 & 0.213 & 0.421 & 4.0 & 2.4 \\
\hline (12) PMET & 0.556 & 0.015 & 0.137 & 4 & 2.5 & (19) CONST & 0.487 & 0.000 & 0.000 & 2.0 & 1.2 \\
\hline (11) HIE & 0.498 & 0.009 & 0.223 & 9 & 5.7 & (25) ALBI & 0.896 & 0.000 & 0.000 & 5.0 & 3.0 \\
\hline (10) $\mathrm{MnM}$ & 0.602 & 0.027 & 0.035 & 4 & 2.5 & (29) APUB & 0.750 & 0.000 & 0.000 & 2.0 & 1.2 \\
\hline (19) CONST & 0.472 & 0.000 & 0.000 & 2 & 1.3 & (21) HOTR & 0.719 & 0.001 & 0.001 & 5.0 & 3.0 \\
\hline (25) ALBI & 0.921 & 0.000 & 0.001 & 8 & 5.0 & (30) SERV & 0.756 & 0.002 & 0.000 & 4.0 & 2.4 \\
\hline (5) MAD & 0.485 & 0.019 & 0.028 & 5 & 3.1 & (5) MAD & 0.549 & 0.051 & 0.218 & 8.0 & 4.8 \\
\hline (29) APUB & 0.689 & 0.081 & 0.065 & 5 & 3.1 & (1) AGRO & 0.661 & 0.069 & 0.116 & 4.0 & 2.4 \\
\hline (17) MANUF & 0.683 & 0.071 & 0.307 & 5 & 3.1 & (3) ALI & 0.446 & 0.039 & 0.083 & 4.0 & 2.4 \\
\hline (30) SERV & 0.737 & 0.027 & 0.011 & 6 & 3.8 & (27) EDU & 0.891 & 0.000 & 0.000 & 1.0 & 0.6 \\
\hline (27) EDU & 0.873 & 0.000 & 0.000 & 1 & 0.6 & $\begin{array}{l}\text { (28) SALUD } \\
\text { Industrias orientadas al Mercado }\end{array}$ & 0.750 & 0.000 & 0.001 & 3.0 & 1.8 \\
\hline $\begin{array}{l}\text { (28) SALUD } \\
\text { Industrias orientadas al Mercado }\end{array}$ & 0.741 & 0.000 & 0.000 & 3 & 1.9 & Interno & 0.631 & 0.056 & 0.150 & 114 & 68.7 \\
\hline Interno & 0.650 & 0.030 & 0.113 & 96 & 60.4 & & & & & & \\
\hline (1) AGRO & 0.744 & 0.024 & 0.082 & 5 & 3.1 & & & & & & \\
\hline (3) ALI & 0.372 & 0.035 & 0.042 & 6 & 3.8 & & & & & & \\
\hline (4) TEX & 0.478 & 0.046 & 0.025 & 4 & 2.5 & (14) ECOM & 0.547 & 0.454 & 0.458 & 0.0 & 0.0 \\
\hline (22) TRANS & 0.713 & 0.046 & 0.067 & 9 & 5.7 & (15) MELEC & 0.639 & 0.332 & 0.512 & 1.0 & 0.6 \\
\hline \multirow[t]{2}{*}{ Industrias con doble orientación } & 0.577 & 0.038 & 0.054 & 24 & 15.1 & (16) ETRANS & 0.499 & 0.418 & 0.279 & 2.0 & 1.2 \\
\hline & & & & & & (20) COM & 0.734 & 0.112 & 0.001 & 27.0 & 16.3 \\
\hline (7) PET & 0.621 & 0.194 & 0.115 & 6 & 3.8 & (4) TEX & 0.557 & 0.293 & 0.320 & 3.0 & 1.8 \\
\hline (21) HOTR & 0.809 & 0.113 & 0.074 & 2 & 1.3 & (17) MANUF & 0.529 & 0.354 & 0.253 & 3.0 & 1.8 \\
\hline (20) COM & 0.848 & 0.160 & 0.002 & 28 & 17.6 & (2) MIN & 0.816 & 0.333 & 0.020 & 6.0 & 3.6 \\
\hline (2) MIN & 0.672 & 0.224 & 0.073 & 3 & 1.9 & $\begin{array}{l}\text { (22) TRANS } \\
\text { Industrias netamente }\end{array}$ & 0.626 & 0.068 & 0.015 & 10.0 & 6.0 \\
\hline Industrias netamente exportadoras & 0.737 & 0.173 & 0.066 & 39 & 24.5 & exportadoras & 0.618 & 0.296 & 0.232 & 52 & 31.3 \\
\hline
\end{tabular}

Nota: VA / VBP = Relación Valor Agregado y Valor Bruto de la Producción; X / VBP = Parte de la producción destinada a las exportaciones; $\mathrm{M} / \mathrm{VBP}=$ Componente de Importaciones.

Fuente: Elaboración propia con datos de las matrices insumo - producto del Instituto Nacional de Estadísticca, Geografía e Informática (INEGI), México y de 2003 del STAN Structural Analysis Database, OCDE.

Para el segundo año, el panorama cambia radicalmente, pese al incremento de alrededor de 15 puntos porcentuales en el valor agregado de las actividades dedicadas a abastecer las necesidades del mercado interno, las importaciones se reducen significativamente -20 puntos - y las exportaciones apenas tienen una variación de 4 puntos. Las actividades netamente exportadoras, con una participación del 80 por ciento en las ventas al exterior, incrementan sus importaciones hasta absorber el 50 por ciento del total, mientras el valor agregado resulta del 38 por ciento. El comportamiento de las importaciones, tanto de las ramas orientadas al mercado interno como de las exportadoras, demuestran la elevada dependencia de la economía mexicana y, con ello la poca articulación de la economía mexicana.

Estos datos demuestran que las ramas más dinámicas de la economía mexicana han sido tradicionalmente dependientes de las importaciones y generan relativamente menos valor agregado. Tal argumento puede corroborarse con el componente importador, es decir, con la relación M/VBP, el cual muestra que las actividades que hacen dinámica a la economía son las de mayor contenido de insumos importados, 
independientemente del tipo de mercado que abastezcan. La relación VA/VBP demuestra que son las industrias del mercado interno las que tienen la más alta relación y, como es lógico, las más exportadoras las que tienen un mayor cociente X/VBP (Cuadro 4).

De acuerdo a la Gráfica 2, hay un cambio sustancial en la forma en cómo se relacionan los sectores entre sí, por medio de los Cl. Destaca la posición central de las actividades comerciales en los dos años de estudio, fundamentalmente en 1980. Seguramente, ello se explica por el mismo carácter intermediario del sector en cuestión. En el primer año, otra actividad internacionalizada y relativamente articulada es Servicios asociados a los transportes, mientras el resto de las industrias exportadoras se localizan en la periferia, demostrando su baja articulación al aparato productivo mexicano. En lo referente a las actividades dirigidas al mercado interno, tienden a colocarse en un segundo plano o en posiciones más periféricas. De tal forma que el análisis de la gráfica de 1980 confirma, nuevamente, la poca articulación de las industrias para el mercado interno, debido a la alta dependencia a las importaciones, característica del período sustitutivo de importaciones.

En el año 2003, la posición de las industrias que abastecen al mercado interno cambia sustancialmente; esto es, la red se vuelve más densa para las actividades de alto consumo autónomo. El número de grados promedio de este tipo de industrias aumenta de 4.4 a 5.1, encontrándose algunas de éstas actividades en una ubicación más central y de mayor articulación, como es el caso de Actividades de negocios, Química, Petróleo y Plásticos. En cuanto a las ramas exportadoras, se muestra una reducción de la cantidad de grados promedio de 9.7 a 6.5, con lo que establecemos que, a excepción de Comercio y Servicios de transportes, muchas de las industrias exportadoras tienden a localizarse en posiciones periféricas, destacando por su casi total desarticulación Equipo de transporte, Maquinaria eléctrica y Equipo de cómputo. 
Gráfica 2

México

Red de interrelaciones por tipo de mercado

Vinculaciones Importantes, 1980

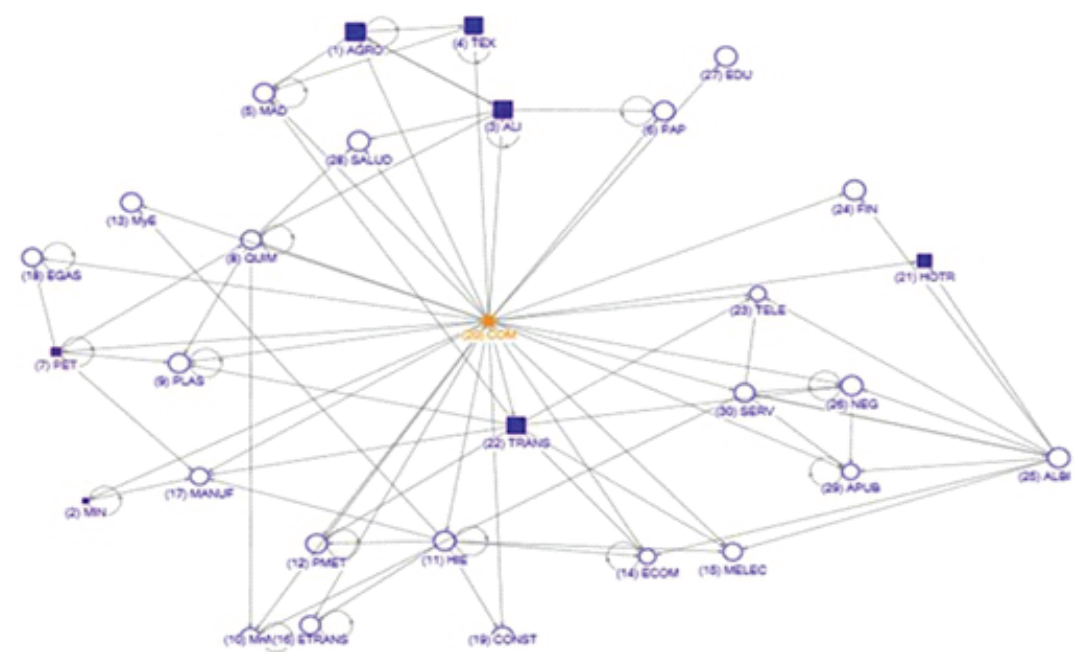

Vinculaciones Importantes, 2003

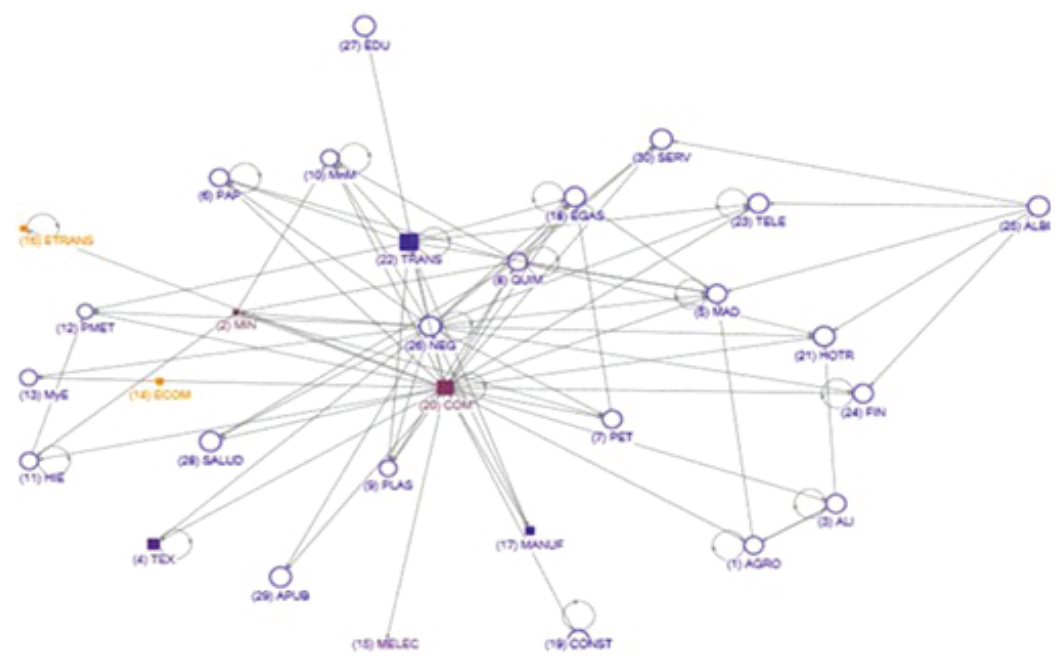

Fuente: Elaborado a partir de las matriz insumo - producto, publicadas por INEGI (1980) y STAN (OCDE), 2008 
En síntesis, el modelo de industrialización de México se ha caracterizado por la dependencia, la subordinación y el estancamiento (Ortiz, 1994; Dussel, 1997), presentando un desenvolvimiento económico mediocre e incierto. En general, parece ser un país estancado, dualizado y polarizado (Molina y Zárate, 2009). Así, durante el primer año de estudio, demuestra baja competitividad internacional, un mercado interno altamente dependiente de importaciones y desarticulado, manifestando que el proceso de ISI fue indiscriminado, contrario a lo que la misma CEPAL proponía. Para el año 2003, el modelo es totalmente a la inversa, se busca la inserción de la economía a las prácticas de fragmentación productiva, en industrias que se distinguen por un mayor potencial tecnológico, pero absolutamente desarticuladas. En contraparte, pese a la importancia creciente del mercado interno - en términos de la generación de valor agregado y cierta ganancia en su articulación productiva - no es dinámico. En suma, la evolución de la economía mexicana refleja un fenómeno de dualización productiva, con el dinamismo de un sector exportador que se rige bajos sus propias pautas independientemente del desenvolvimiento de la actividad interna. Así, mientras las industrias más exportadoras no se articulan al conjunto de la actividad y, por lo mismo, no generan efectos de derrame hacia el resto de la economía, las ramas destinadas a cubrir el mercado interno, no son dinámicas pese a su ligera capacidad de articulación. Con lo cual genera límites a la posibilidad de mantener un crecimiento sostenido.

\subsection{La dinámica del Mercado Interno y las actividades exportadoras en Corea del Sur}

Corea del Sur puede entenderse como un caso opuesto al español, con un fortalecimiento de su mercado interno, sin compartir los mismos rasgos que México. En 1980, diecinueve actividades aparecen de alto consumo autónomo (Negocios, Telecomunicaciones, Finanzas, Maquinaria y equipo, Maquinaria eléctrica, Electricidad y gas, Minería, Petróleo, Papel, Minerales no metálicos, Bienes inmuebles, Administración pública, Construcción, Otros servicios, Hoteles y restaurantes, Madera, Alimentos, Salud y Educación), con una participación del 54\% en el valor agregado, del $53 \%$ en las importaciones y del 14\% en las exportaciones. Por su parte, las nueve industrias netamente exportadoras (Equipo de cómputo, Equipo de transporte, Hierro, Plástico, Productos de metal, Comercio, Textiles, Otras manufacturas y Servicios asociados a los transportes) participaban con el 30\% en el valor agregado, 28.6 en las importaciones y casi el $80 \%$ en las exportaciones. En tanto, únicamente dos actividades de doble orientación (Química y Productos agrícolas) contribuían con 15\% en valor agregado, 18 en importaciones y 7 en exportaciones (Cuadro 5).

Corea del Sur

Contribución en valor agregado, exportaciones e importaciones por

Cuadro 5 tipo de mercado, 1980 y 2005 (porcentajes de participación)

\begin{tabular}{lcrrrrr}
\hline & \multicolumn{2}{c}{ Valor Agregado } & \multicolumn{2}{c}{ Exportaciones } & \multicolumn{2}{c}{ Importaciones } \\
& 1980 & 2005 & 1980 & 2005 & 1980 & 2005 \\
\hline Industrias orientadas al mercado interno & 54.3 & 61.6 & 13.8 & 13.3 & 53.0 & 42.8 \\
Industrias con doble orientación & 15.2 & 9.9 & 6.8 & 8.7 & 18.4 & 9.4 \\
Industrias netamente exportadoras & 30.5 & 28.5 & 79.5 & 78.0 & 28.6 & 47.7 \\
\hline
\end{tabular}

Fuente: Elaboración propia con datos de las matrices insumo-producto de 1980 de Economic Statistics System, The Bank of Korea, y de 2005 del STAN Structural Anslysis Database, OCDE. 
Para 2005, los cambios que tienen lugar en la estructura económica de Corea, no sólo tienen que ver con el incremento en el número de ramas dedicadas a abastecer el mercado interno, sino también con modificaciones en la orientación productiva de algunas de las actividades. Así, del grupo de industrias dirigidas al mercado interno, dos cambian su orientación por el mercado de exportación (Petróleo y Maquinaria y equipo), tres que en 1980 eran netamente exportadoras se vuelven de alto consumo autónomo (Plásticos, Productos de metal y Otras manufacturas) y de las dos ramas que en el primer año son de doble orientación, una (Productos agrícolas) se pasa al grupo abastecedor del mercado interno y la otra (Química) se vuelve netamente exportadora. Las industrias de doble orientación - Hierro y Comercio - se constituyen como netamente exportadoras.

Corea del Sur

Cuadro 6 Comportamiento de las industrias por tipo de mercado, 1980 y 2005

\begin{tabular}{|c|c|c|c|c|c|c|c|c|c|c|c|}
\hline \multirow[b]{2}{*}{ Industrias por tipo de mercado } & \multicolumn{4}{|c|}{1980} & \multirow[b]{2}{*}{$\begin{array}{c}\text { Particip } \\
\%\end{array}$} & \multirow[b]{2}{*}{ Industrias por tipo de mercado } & \multirow[b]{2}{*}{ VANBP } & \multicolumn{3}{|c|}{2005} & \multirow[b]{2}{*}{$\begin{array}{c}\text { Particip } \\
\%\end{array}$} \\
\hline & VAVBP & $X N B P$ & $M N B P$ & Grado & & & & $X N B P$ & $M N B P$ & Grado & \\
\hline (26) NEG & 0.016 & 0.003 & 0.016 & 7 & 3.6 & (23) TELE & 0.513 & 0.018 & 0.032 & 5 & 2.3 \\
\hline (23) TELE & 0.888 & 0.060 & 0.040 & 4 & 2.0 & (24) FIN & 0.643 & 0.028 & 0.043 & 7 & 3.3 \\
\hline (24) FIN & 0.744 & 0.031 & 0.012 & 3 & 1.5 & (26) NEG & 0.656 & 0.060 & 0.112 & 13 & 6.0 \\
\hline (13) MyE & 0.726 & 0.044 & 0.590 & 3 & 1.5 & (15) MELEC & 0.434 & 0.158 & 0.219 & 6 & 2.8 \\
\hline (15) MELEC & 0.487 & 0.116 & 0.271 & 7 & 3.6 & (2) MIN & 0.980 & 0.001 & 0.953 & 1 & 0.5 \\
\hline (18) EGAS & 0.424 & 0.007 & 0.000 & 4 & 2.0 & (18) EGAS & 0.410 & 0.001 & 0.002 & 6 & 2.8 \\
\hline (2) MIN & 0.972 & 0.010 & 0.907 & 1 & 0.5 & (10) $\mathrm{MnM}$ & 0.409 & 0.051 & 0.134 & 11 & 5.1 \\
\hline (7) PET & 0.302 & 0.010 & 0.140 & 18 & 9.2 & (12) PMET & 0.353 & 0.121 & 0.058 & 8 & 3.7 \\
\hline (6) PAP & 0.387 & 0.052 & 0.157 & 5 & 2.6 & (9) PLAS & 0.371 & 0.156 & 0.092 & 6 & 2.8 \\
\hline (10) $\mathrm{MnM}$ & 0.340 & 0.129 & 0.053 & 9 & 4.6 & (29) APUB & 0.815 & 0.001 & 0.002 & 2 & 0.9 \\
\hline (25) ALBI & 0.780 & 0.001 & 0.004 & 3 & 1.5 & (5) MAD & 0.424 & 0.012 & 0.222 & 14 & 6.5 \\
\hline (29) APUB & 0.508 & 0.001 & 0.014 & 2 & 1.0 & (19) CONST & 0.453 & 0.001 & 0.000 & 2 & 0.9 \\
\hline (19) CONST & 0.410 & 0.003 & 0.000 & 5 & 2.6 & (25) ALBI & 0.754 & 0.005 & 0.008 & 5 & 2.3 \\
\hline (30) SERV & 0.588 & 0.034 & 0.059 & 5 & 2.6 & (1) AGRO & 0.639 & 0.011 & 0.141 & 7 & 3.3 \\
\hline (21) HOTR & 0.623 & 0.103 & 0.073 & 7 & 3.6 & (17) MANUF & 0.427 & 0.143 & 0.185 & 13 & 6.0 \\
\hline (5) MAD & 0.176 & 0.271 & 0.026 & 7 & 3.6 & (30) SERV & 0.335 & 0.025 & 0.034 & 13 & 6.0 \\
\hline (3) ALI & 0.286 & 0.029 & 0.077 & 3 & 1.5 & (21) HOTR & 0.446 & 0.045 & 0.075 & 5 & 2.3 \\
\hline (28) SALUD & 0.524 & 0.000 & 0.003 & 10 & 5.1 & (6) PAP & 0.429 & 0.072 & 0.119 & 8 & 3.7 \\
\hline (27) EDU & 0.784 & 0.000 & 0.004 & 3 & 1.5 & (3) ALI & 0.380 & 0.041 & 0.130 & 4 & 1.9 \\
\hline \multirow[t]{2}{*}{ Industrias orientadas al Mercado Interno } & 0.524 & 0.048 & 0.129 & 106 & 54.1 & (28) SALUD & 0.691 & 0.001 & 0.060 & 5 & 2.3 \\
\hline & & & & & & (27) EDU & 0.560 & 0.000 & 0.007 & 1 & 0.5 \\
\hline (8) QUIM & 0.417 & 0.076 & 0.213 & 13 & 6.6 & Industrias orientadas al Mercado Interno & 0.530 & 0.045 & 0.125 & 142 & 66.0 \\
\hline (1) AGRO & 0.755 & 0.045 & 0.191 & 6 & 3.1 & & & & & & \\
\hline \multirow[t]{2}{*}{ Industrias con doble orientación } & 0.586 & 0.060 & 0.202 & 19 & 9.7 & (11) HIE & 0.354 & 0.131 & 0.200 & 8 & 3.7 \\
\hline & & & & & & (20) COM & 0.604 & 0.098 & 0.020 & 16 & 7.4 \\
\hline (14) ECOM & 0.486 & 0.307 & 0.293 & 5 & 2.6 & Industrias con doble orientación & 0.479 & 0.115 & 0.110 & 24 & 11.2 \\
\hline (16) ETRANS & 0.524 & 0.194 & 0.343 & 3 & 1.5 & & & & & & \\
\hline (11) $\mathrm{HIE}$ & 0.298 & 0.170 & 0.189 & 11 & 5.6 & (14) ECOM & 0.451 & 0.465 & 0.269 & 5 & 2.3 \\
\hline (9) PLAS & 0.322 & 0.292 & 0.110 & 6 & 3.1 & (13) MyE & 0.441 & 0.205 & 0.236 & 6 & 2.8 \\
\hline (12) PMET & 0.345 & 0.400 & 0.125 & 6 & 3.1 & (8) QUIM & 0.373 & 0.221 & 0.215 & 13 & 6.0 \\
\hline (20) COM & 0.688 & 0.122 & 0.012 & 17 & 8.7 & (16) ETRANS & 0.268 & 0.415 & 0.067 & 5 & 2.3 \\
\hline (4) TEX & 0.275 & 0.356 & 0.057 & 7 & 3.6 & (7) PET & 0.414 & 0.204 & 0.160 & 6 & 2.8 \\
\hline (17) MANUF & 0.375 & 0.493 & 0.078 & 9 & 4.6 & (4) TEX & 0.445 & 0.269 & 0.203 & 5 & 2.3 \\
\hline (22) TRANS & 0.505 & 0.309 & 0.083 & 7 & 3.6 & (22) TRANS & 0.511 & 0.277 & 0.145 & 9 & 4.2 \\
\hline Industrias netamente exportadoras & 0.424 & 0.294 & 0.143 & 71 & 36.2 & Industrias netamente exportadoras & 0.415 & 0.294 & 0.185 & 49 & 22.8 \\
\hline
\end{tabular}

Nota: VA / VBP = Relación Valor Agregado y Valor Bruto de la Producción; X / VBP = Parte de la producción destinada a las exportaciones; $\mathrm{M} / \mathrm{VBP}=$ Componente de Importaciones.

Fuente: Elaboración propia con datos de las matrices insumo-producto de 1980 de Economic Statistics System, The Bank of Korea. 
Los cambios en las participaciones en las tres variables consideradas - sobre todo, en valor agregado e importaciones - asemejan lo ocurrido en México durante los dos períodos. En 1980 se observa alta dependencia a las compras provenientes del exterior de los sectores de alto consumo autónomo, posiblemente explicado por las características del modelo sustitutivo de importaciones. Para el segundo año, se presenta un incremento significativo del peso relativo en esta misma variable del grupo exportador. De tal manera que la internacionalización de la economía surcoreana, también demuestra que la actual configuración internacional de la producción requiere de elevadas importaciones temporales que serán procesadas en el país y, posteriormente, se destinarán al mercado de exportación. Un dato curioso que lo aleja del comportamiento de México, es que pese a las modificaciones que tienen lugar en el contenido de importaciones en la producción de cada tipo de industrias, éstas no son tan dramáticas como ocurre en México, por lo que la relación M/VBP se mantiene relativamente estable tanto en los sectores que proveen al mercado interno como en los netamente exportadores. Las mayores diferencias son para el grupo de actividades de doble orientación, cuyo aporte de valor agregado y contenido importador disminuyen mientras la parte de la producción que se destina a las exportaciones aumenta (Cuadro 6).

La red de interrelaciones importantes, tiende a hacerse más densa, aumentando el número de grados de 196 a 215 (Gráfica 3). Las industrias orientadas al mercado interno ganan cohesión, no solo se incrementa el número de grados promedio de 5.6 a 6.8, sino que también toman posiciones más centrales. En 1980, eran las industrias de doble orientación - como Química - o las más exportadoras - Hierro y Comercio - las que mantenían una ubicación más central, destaca también Otras manufacturas, que pese a ser netamente exportadora era una actividad muy articulada. Para 2005, los sectores exportadores se mueven a posiciones más periféricas, sin necesariamente, estar desarticulados, de tal manera que el número de grados promedio muestra una ligera reducción de 7.9 a 7, mientras algunos sectores orientados al mercado interno, dejan de estar en ubicaciones periféricas. 
Gráfica 3

Corea del Sur

Red de interrelaciones por tipo de mercado

Vinculaciones Importantes, 1980

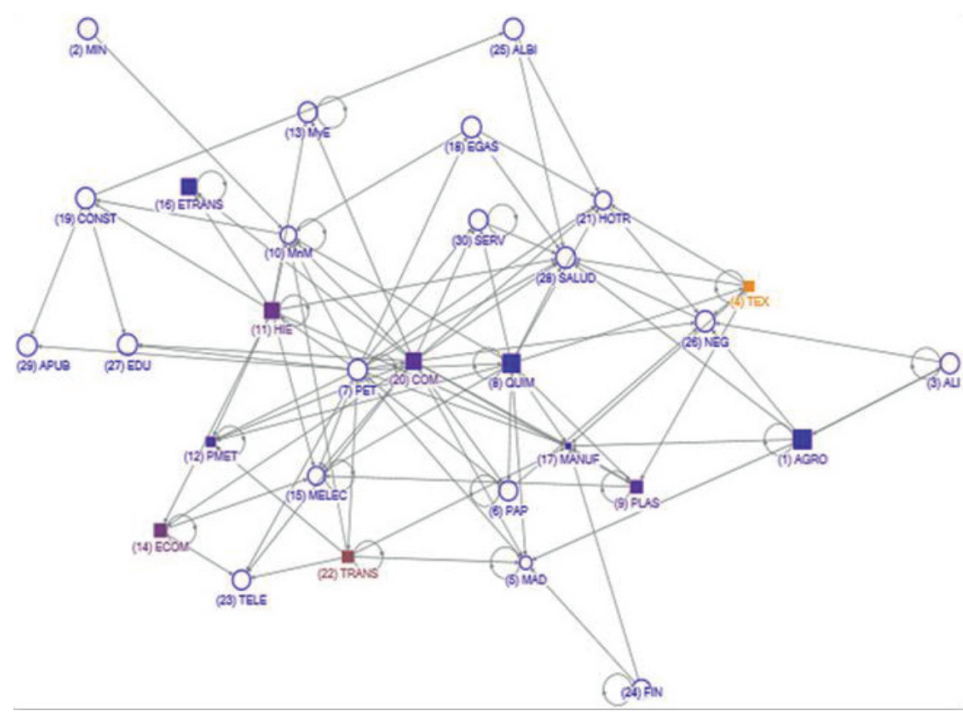

Vinculaciones Importantes, 2005

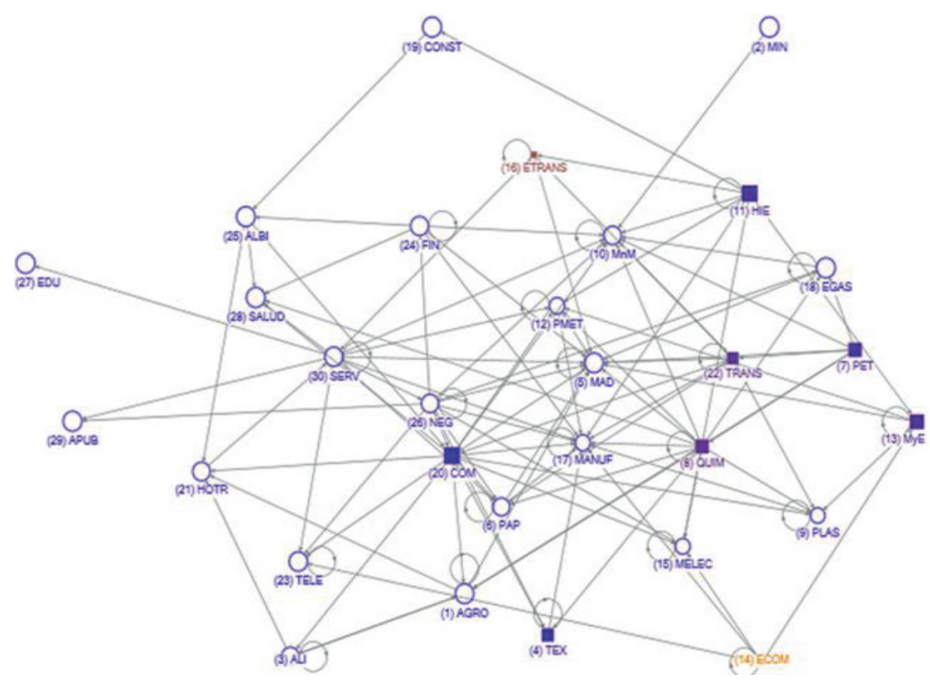

Fuente: Elaboración propia con datos de Economic Statistics System, The Bank of Korea y STAN, OCDE. 
Por un lado, el número de industrias con mayor vocación interna aumenta en tres de 1980 a 2005, demostrando también una ganancia de articulación, la cual se refleja tanto en una reducción en la participación en las importaciones, el aumento de 7 puntos en el valor agregado, como en la mayor densidad en los grados. Pese a una aparente consolidación del mercado interno que implica en cierta medida la reducción en la cantidad de industrias exportadoras, estas actividades no presentan un comportamiento semejante al caso mexicano, aunque se da una pérdida en la cantidad de grados promedio (de 0.9), dichas actividades están articuladas y presentan una dependencia menor a las importaciones.

El modelo surcoreano presenta similitudes importantes con la propuesta de la CEPAL, además del papel protagonista que debía tener el Estado en la planificación y dirección de la actividad económica, la importancia del progreso tecnológico (Amsdem, 2007) y el papel de las empresas trasnacionales (Kerner, 2003), tiene lugar un proceso de industrialización orientado a la exportación para resolver la saturación del mercado interno, muy parecido al planteamiento que proponía la corriente estructuralista (Fajnzylber, 1983 y Sunkel, 1991). A su vez, utiliza el mercado interno para ganar especialización, lo que junto con políticas comerciales e industriales proteccionistas (Chang, 2003), fueron cruciales para lograr una exitosa inserción a la dinámica internacional.

Con el paso del tiempo, Corea del Sur mantiene un estilo de desarrollo más consolidado, no solo cuenta con un sector exportador altamente dinámico, sino que además está articulado con la estructura productiva interna. El país ha sido capaz de integrar a los sectores más avanzados a las llamadas cadenas globales de valor en posiciones generadoras de alto valor agregado y contenido tecnológico y, en ocasiones, sus empresas han sido las principales promotoras de prácticas de fragmentación y deslocalización productiva hacia otras economías. Al mismo tiempo, no descuida el mercado interno, el cual además de articulado muestra un mayor dinamismo en comparación con las otras dos economías, demostrando con ello que la integración económica internacional y el fortalecimiento de la demanda interna, no son alternativas antagónicas sino estrategias complementarias para alcanzar el crecimiento económico sostenido.

\section{Conclusiones}

En la búsqueda de un nuevo estilo de desarrollo, resulta indispensable la integración internacional, pero además es fundamental el fomento al mercado interno, sin olvidar a la articulación productiva como un requisito para el crecimiento económico sostenido. En este sentido, para definir la relevancia del mercado interno frente a la evolución de las actividades más exportadoras, se evaluó la relevancia del mercado interno frente a la evolución de la propia actividad exportadora. De acuerdo con la evidencia empírica presentada, el fomento al mercado interno y los procesos de integración, no son medidas antagónicas sino estrategias complementarias en la búsqueda de una senda de crecimiento sostenido.

La fragmentación productiva tiene diferentes efectos para cada una de las economías analizadas; provocando desarticulación y bajo crecimiento para España y México, como consecuencia de que las ganancias del comercio han quedado restringidas a unos cuantos sectores, teniendo efectos negativos para su respectivo mercado interno y su dinamismo económico. En contraparte, el perfil exportador de Corea del Sur se complementa con un mercado interno más dinámico, facilitando el papel dinamizador de las industrias con mayor capacidad exportadora. 
Por lo anterior, una estructura económica articulada es un elemento imprescindible para lograr un crecimiento económico sostenido. Por lo tanto, siguiendo a los autores estructuralistas latinoamericanos (Prebisch, 1959; Fajnzylber, 1983; Sunkel, 1991), pero añadiendo las condiciones actuales que impone la globalización, afirmamos que son importantes tanto las condiciones que impone la integración internacional y el actuar de las empresas transnacionales, como la fortaleza de un mercado interno dinámico para impulsar o restringir el proceso de crecimiento.

\section{Referencias}

Amsdem, A. (2007), Escape from Empire. The Developing World's Journey Through Heaven and Hell, The MIT Press, primeraedición,Cambridge, Massachusetts,.

Aroche, F. (1996), "Important coefficients and structural change: a multi-layer approach", Economic Systems Research, 8, pp. 235- 246.

Aroche, F. (2002), "Structural Transformations and Important Coeffcients in the North American Economies”.Economic Systems Research, Vol. 14, No. 3, pp. 257 - 273.

Aroche, F. (2005), "Desintegración en la estructura productiva mexicana y el empleo. Los coeficientes importantes y la integración”, en Revista Asturiana de Economía-RAE, No. 33, pp. 3 - 36.

Balassa, B. (1989), Comparative Advantage, Trade Policy and Economic Development, New York University Press, Primera edición, New York.

Chang, Ha-Joon (2003), "Patada a la escalera: La verdadera historia del libre comercio", trabajo presentado en la conferencia "La Mundialización y el mito del libre comercio" (Globalisation and theMythof Free Trade), celebrado en la New SchoolUniversity de Nueva York, 18 de abril de 2003.

Dussel, E. (1997), La Economía de la Polarización, UNAM - JUS, Primera edición, México, D.F.

Fajnzylber, F. (1983), La industrialización trunca de América Latina. Ed. México, Editorial Nueva Imagen, Primera edición, México, D. F.

Feenstra, R. (1998), "Integration of trade and disintegration of production”. JournalofEconomicPerspectives, Vol. 12, No. 4, pp. 31-50.

García, S. y Ramos, C. (2003), "Las redes sociales como herramienta de análisis estructural Input - Output", Revista Hispana para el análisis de Redes Sociales, Vol. 4, No. 5, pp. 2 - 21.

Gereffi, G. (2001), "Las cadenas productivas como marco analítico para la globalización”. En Revista Problemas del Desarrollo, IIEc-UNAM, abril-junio Vol. 32, No. 125, pp. 9-37.

Gereffi, Humphrey, Kaplinsky y Sturgeon (2001), Globalisation, Value Chains and Development.IDS Bulletin 32.3. InstituteofDevelopmentStudies, pp. 1-12.

Godínez. J. A. y Ángeles, M. C. (2006), "Desverticalización productiva, outsourcing y efectos sobre el empleo en la relación México - Estados Unidos 1987 - 2003", Revista Aportes, Vol. XI, No. 033, pp. 26 - 36.

Harary, F.(1969), Graph Theory.Addison - Wesley Publishing Company, Reading,Massachusetts,

Hummels,Rapoport, y Yi, (1998), "Vertical Specialization and the Changing Nature of World Trade",Economic Policy Review, Vol. 4, No. 2, pp. 79 - 99.

Hummels, Jun Ishii y Yi, (1999), "The nature and growth of vertical specialization in world trade", Research Paper, No. 9718, pp. 1 - 39.

Kaldor, N. (1966), Causes of the Slow Rate of Economic Growth of the United Kingdom, Primera edición, Cambridge. 
Kaplinsky, R. (1998), Globalisation, industrialisation and sustainable growth: the pursuit of the nth rent. IDS Discussion Paper 365, http://citeseerx.ist.psu.edu/viewdoc/download?doi=10.1.1.475.6130\&rep=rep1\& type $=$ pdf.

Kaplinsky, R. y Kaplan, D. (1999), "Trade and Industrial Policy on an Uneven Playing Field: The Case of the Deciduous Fruit Canning. Industry in South Africa”, WorldDevelopment, Vol. 27, No. 10, pp. 1787-1801.

Krueger, A. (1990), “Comparative Advantage and Development Policy Twenty Years Later", en Krueger (ed): Perspectives on Trade and Development, London,Harvester Wheatsheaf.

Krugman, P. (1979), "Increasing Returns, Monopolistic Competition, and International Trade”, enJournal of International Economics, Vol. 9, No. 4, pp. 469 - 479.

Miller, R. y Blair, P. (2009), Input - Output Analysis. Foundations and Extensions, Cambridge University Press, Primera edición, Cambrigde.

Molina, T. y Zárate, R. (2009), La industrialización orientada a la exportación: ¿una estrategia de desarrollo para México?, Siglo XXI e IIEc - UNAM, Primera edición, México.

Molina, T. (2016), La articulación productiva como elemento clave para el desarrollo económico: la experiencia de España, Corea del Sur y México frente al proceso de internacionalización de la producción, 1980 - 2000, Tesis Doctoral, Universidad Complutense de Madrid, España.

Ortiz, E. (1994). Competencia y crisis en la economía mexicana. Siglo XXI - UAM, Primera edición, México.

Ortiz, E. (2012) "Modelos de desarrollo: integración versus globalización Evaluación y perspectivas actuales. El caso de México". En Ortiz (coord.), Globalización versus desarrollo: Las nuevas condiciones para un proceso de cambio estructural viable y sustentable.UAM-X, Primera edición,México.

Prebisch, R. (1959), "Commercial policy in the underdeveloped countries". The American Economic Review, Vol. 49 , No. 2, pp. $322-329$.

Samuelson, P. (1948) "International trade and equalization of factor prices", en Economic Journal, No. 58, pp. 163- 84.

Schintke, J. y Stäglin, R. (1988), "Important input coefficients in market transaction tables and production flow tables”, enCiaschini, M. (edit), Input - Output Analysis. CurrentDevelopments, Chapman and Hall, Londres.

Sunkel, O. (1991), "Del desarrollo hacia adentro al desarrollo desde dentro". En Revista Mexicana de Sociología, Vol. 53, No. 1, pp. 3 - 42.

Tarancón, M.A. (2004), "Medición de la sensibilidad de la estructura productiva al desarrollo sostenible", en Problemas del Desarrollo, Vol. 35, No.139, pp. 122 - 139.

Tarancón, M, Callejas, F, Dietzenbacher, E. and Lahr, M. L. (2008), "A Revision of the Tolerable Limits Approach: Searching for the Important Coefficients", Economic Systems Research, No. 20, pp. 75 - 95.

Thirlwall, A. (2003), La Naturaleza del Crecimiento Económico, Fondo de Cultura Económica, Primera edición, México.

Thorbecke, W. (2015), "Understanding Japan's Capital Goods Exports”, Research Institute of Economy, Trade and Industry. RIETI DiscussionPaper Series 15-E-044, pp. 1 - 30.

Zárate, R. y Molina, T. (2017), La industrialización orientada a la articulación, una opción para el desarrollo frente al proceso de fragmentación productiva a nivel mundial, México, CEPAL - UNAM - IIEc. 